\title{
Postoperative Health-Related Quality of Life of Cervical Cancer Patients - A Comparison between the Wertheim-Meigs Operation and Total Mesometrial Resection (TMMR)
}

\author{
Die postoperative gesundheitsbezogene Lebensqualität von Zervixkarzinompatientinnen - \\ Ein Vergleich zwischen der Wertheim-Meigs-Operation und der Totalen Mesometrialen Resektion (TMMR)
}

Authors

Affiliations
E. Sowa ${ }^{1}$, S. Kuhnt ${ }^{2}$, A. Hinz ${ }^{2}$, C. Schröder ${ }^{2}$, T. Deutsch ${ }^{3}$, K. Geue ${ }^{2}$

${ }^{1}$ Klinik für Gynäkologie und Geburtshilfe, Klinikum St. Georg gGmbH Leipzig, Leipzig

${ }^{2}$ Department of Medical Psychology and Medical Sociology, University Leipzig, Leipzig

${ }^{3}$ Selbständige Abteilung für Allgemeinmedizin, Universität Leipzig, Leipzig

\begin{abstract}
Key words
- cervical cancer

- cervix

- gynaecology

Schlüsselwörter

- Zervixkarzinom

- Zervix

- Gynäkologie
\end{abstract}

Deutschsprachige Zusatzinformationen online abrufbar unter: www.thieme-connect.de/ ejournals/toc/gebfra

received 20.12.2013

revised 14.5.2014

accepted 20.5.2014

Bibliography

DOI http://dx.doi.org/

10.1055/s-0034-1368600

Geburtsh Frauenheilk 2014; 74 :

670-676 @ Georg Thieme

Verlag KG Stuttgart · New York . ISSN 0016-5751

Correspondence

Kristina Geue, Dipl.-Psych.

University Leipzig

Department of

Medical Psychology and

Medical Sociology

Philipp-Rosenthal-Straße 55

04107 Leipzig

kristina.geue@

medizin.uni-leipzig.de

\section{Abstract \\ $\nabla$}

Introduction: The present study compares for the first time the standard therapy for cervical cancer in FIGO-stages IB-IIB, radical hysterectomy according to the Wertheim-Meigs operation, with the newly developed, nerve-sparing surgical technique, total mesometrial resection (TMMR) with regard to postoperative, health-related quality of life.

Method: In the framework of a multicentre, retrospective cohort study a total of 110 cervical cancer patients were interviewed once by means of the European Organisation for Research and Treatment of Cancer Quality of Life Questionnaire (EORTC QLQ-C30) and the cervical cancer module (EORTC QLQ-CX24). The influence of the surgical method was investigated by analysis of covariance under control of age and the time elapsed between treatment and interview.

Results: An influence of the therapeutic method was demonstrated in the EORTC scales physical function $(p=0.047)$, role function $(p=0.016)$, fatigue $(p=0.028)$, pain $(p=0.018)$, shortness of breath $(p=0.034)$, lack of appetite $(p=0.006)$ and diarrhoea $(p=0.012)$ in favour of the 74 women treated by TMMR. With regard to cognitive, emotional and social functioning as well as cervical cancer-specific symptoms, no significant differences between the therapy groups were found.

Conclusion: The findings presented in this study suggest a superiority of TMMR in comparison to the previously employed radical hysterectomy according to Wertheim-Meigs with regard to the postoperative quality of life, especially in the fields of physical activity and fatigue. This needs to be validated in the course of prospective, multicentre studies. In addition, it must be clarified as to what extent the found effects are, in particular, due to the omission of an additional radiotherapy.

\section{Zusammenfassung \\ $\nabla$}

Einleitung: Die vorliegende Studie vergleicht erstmals die Standardtherapie des Zervixkarzinoms der FIGO-Stadien IB-IIB, die radikale Hysterektomie nach Wertheim-Meigs-Operation, mit der neu entwickelten nervenschonenden Operationstechnik, der totalen mesometrialen Resektion (TMMR) hinsichtlich der postoperativen gesundheitsbezogenen Lebensqualität.

Methode: Im Rahmen einer multizentrischen, retrospektiven Kohortenstudie wurden insgesamt 110 Zervixkarzinompatientinnen postoperativ einmalig mit dem European Organisation for Research and Treatment of Cancer Quality of Life Questionnaire (EORTC QLQ-C30) und dem Zervixkarzinom-Modul (EORTC QLQ-CX24) befragt. Der Einfluss der Operationsmethode wurde mittels Kovarianzanalysen unter Kontrolle des Lebensalters und der vergangenen Zeit zwischen Therapie und Interview untersucht.

Ergebnisse: Es zeigte sich ein Einfluss der Therapiemethode in den EORTC-Skalen körperliche Funktion $(p=0,047)$, Rollenfunktion $(p=0,016)$, Fatigue $(p=0,028)$, Schmerzen $(p=0,018)$, Kurzatmigkeit $(p=0,034)$, Appetitlosigkeit $(p=0,006)$ und Diarrhö $(p=0,012)$ zugunsten der 74 TMMRbehandelten Frauen. Bezüglich der kognitiven, emotionalen und sozialen Funktionsfähigkeit sowie zervixkarzinomspezifischer Symptome wurden keine signifikanten Unterschiede zwischen den Therapiegruppen gefunden.

Schlussfolgerung: Die vorliegenden Befunde legen eine Überlegenheit der TMMR im Vergleich zur bisherigen radikalen Hysterektomie nach Wertheim-Meigs bezüglich der postoperativen Lebensqualität, insbesondere im körperlichen Bereich und der Fatigue, nahe. Dies sollte im Rahmen von prospektiven, multizentrischen Studien verifiziert werden. Zudem sollte geklärt werden, inwieweit die gefundenen Effekte insbesondere 
auf den Verzicht einer zusätzlichen Strahlentherapie zurückzuführen sind.

\section{Introduction}

Worldwide, cervical cancer is the third most frequent cancer disease in women. In Germany it is the third most frequent genital cancer in women. In 2008 the age-standardised incidence was 9.5 per 100000 citizens. The 5-year survival rate was $65 \%$ and the average age at disease onset was about 52 years, i.e., markedly lower than the average age for the onset of cancer in general in women [1,2]. For the occurrence of cervical cancer a prior infection with a high-risk subtype of human papilloma virus (HPV) is necessary [3]. Since March 2007 vaccination against the HPV subtypes 16 and 18 is recommended in Germany for females aged between 12 and 17 years [4]. The early detection of cervical cancer has been a component of guidelines for cancer screening for many years and should now be further developed into an organised screening programme [5].

Depending on the FIGO stage and other factors such as general condition, personal plans for life and a desire to have children, treatment of cervical cancer follows the German S2 guidelines [6]. In FIGO stages IB-IIB the standard treatment comprises radical hysterectomy (RH) according to Wertheim-Meigs with, if necessary, subsequent radiotherapy or with postoperative radiochemotherapy [7]. In a survey of Germany gynaecological departments $71.5 \%$ reported use of the operation according to Wertheim-Meigs [8]. In the meantime, however, beside the standard surgical methods, there are also various nerve-sparing procedures such as, e.g., total mesometrial resection. TMMR was developed by Michael Höckel and colleagues at the University Hospital Leipzig for the stages FIGO IB, IIA and selected IIB patients with the objective of better tumour control simultaneously with lower traumatisation of the female pelvis. The foundation for this surgical technique consists in a new concept of female anatomy based on studies of embryonic and foetal development, hypotheses regarding the spread of tumour cells and knowledge from other nerve-sparing operation techniques. The main principle of this surgical method is extirpation of the tumour-bearing compartment $[9,10]$. This therapy is supposedly associated with a sufficient radicality so that, in spite of histopathological risk factors, the otherwise usually employed radiotherapy with its further considerable bodily impairments can be omitted [10]. As a new, nerve-sparing procedure TMMR is comparable with the standard procedures regarding survival and recurrence rates while, at the same time, having a lower treatment-related morbidity. Thus, in a recent prospective study involving 212 women in FIGO stages IB-IIB who had undergone a TMMR operation, the 5-year probability of survival was $96 \%$ [10].

Beside efforts to improve the treatment procedure with regard to survival, increasing attention is also being paid to the quality of life and its improvement after treatment for cervical cancer. Because of the relatively young age of the patients with cervical cancer and the relatively good prognosis, many of the afflicted women can look forward to a long lifetime. This makes it all the more important to keep therapy-related side effects and impairments in quality of life as low as possible. This is also because physical impairments can arise years after the therapy for cervical cancer [11]. In particular, disorders of bladder and intestinal function, the lymph system and sexual dysfunctions have been reported [11-15]. Some studies have described particularly se- vere impairments in quality of life after radiotherapy or, respectively, the combination of radical hysterectomy and radiotherapy $[16,17]$. Two studies have shown that those patients who underwent a radical hysterectomy suffered less form diarrhoea than those patients who had undergone an additional or an exclusive radiotherapy $[18,19]$. Regarding the short- and long-term complications of therapy it is assumed that the treatment-related morbidities of several radical types of therapy are cumulative [20]. Review articles on nerve-sparing surgical procedures came to the conclusion that these types of therapy appear, in principle, to have a positive impact on the postoperative medical complications [21-23]. Thus, in prospective studies on the early and late complications of TMMR, $62 \%$ of the TMMR patients had no complications, 35\% had 1st degree complications and 9\% had 2nd degree complications of the gastrointestinal tract, the urinary tract, the vascular system, the skin and the peripheral nerves. No patient experienced complications of the 3rd or 4th degree [10]. Studies comparing the quality of life after nerve-sparing surgical methods with that after other treatment methods are as yet rather rare and the results are not consistent. Thus Ditto et al. [24] in a study concerning the impact of a nerve-sparing operation $[25,26]$ with 2 radicality stages on the quality of life of cervical cancer patients could not find any relevant differences. Wu and colleagues [27], on the other hand, investigated the effects of the nerve-sparing operation according to Fujii $[28,29]$ in comparison to those of the standard radical hysterectomy and did indeed find significant differences in the quality of life in favour of the nerve-sparing operation between the two treatment groups. In the present article, for the first time, the standard therapy for cervical cancer of FIGO stages IB-IIB, namely radical hysterectomy according to Wertheim-Meigs, is compared with the newly developed nerve-sparing surgical technique, TMMR, regarding postoperative health-related quality of life.

\section{Methods}

\section{$\nabla$}

\section{Study design}

This is a multicentre, retrospective cohort study with an explorative character. The data of this cross-sectional investigation were gathered from a consecutive patient sample with the help of a standardised questionnaire.

\section{Data collection}

This study was undertaken as cooperation between the gynaecological departments of the University Hospital Leipzig, the Municipal Hospital St. George in Leipzig and a joint practice in Zwickau. Thus, all cervical cancer patients of Leipzig University Hospital who underwent a TMMR procedure in the period from 1999 to 2005 and who attended follow-up examinations were informed about the study. Accordingly, the TMMR data were gathered from a single centre. Recruitment of the cervical cancer patients who underwent a radical hysterectomy $(\mathrm{RH})$ was from the St. Georg Hospital in Leipzig and the Paracelsus clinic in Zwickau. For this the surgical books and patient records were searched for all patients who were treated in this way at the St. George Hospital Leipzig in the period from 1999 to 2005 and in the joint practice in Zwickau in the period from 2000 to 2006. 
Those women were enrolled in the study who had been treated for cervical cancer in the FIGO stages IB-IIB by means of TMMR or radical hysterectomy and who gave their written informed consent. Exclusion criteria were age less than 18 years and insufficient knowledge of the German language. The data were collected postoperatively in the course of an interview or, respectively, by means of a questionnaire and subsequent telephone calls. In the follow-up examinations, the women were personally asked to participate in the study. Data were collected in the period from April 2005 to April 2007.

\section{Instruments}

The sociodemographic data collected included the variables date of birth, partnership status, children, educational level, professional status and net household income. The clinically relevant data such as diagnosis, FIGO stage, grading $(G)$, lymphatic vessel und venous incursions (L, V), menopausal status, therapeutic procedures as well as date of treatment were extracted from the patient records.

The questionnaire EORTC QLQ-C30 (The European Organisation for Research and Treatment of Cancer Quality-of-Life Questionnaire) was used for assessment of the health-related quality of life since it was especially conceived for oncological patients. The 30 items can be summarised to form scales: 5 function scales (physical, emotional, social, cognitive and role function), 3 symptom scales (fatigue, pain, nausea and vomiting), 1 scale for overall quality of life and, in addition, diverse single items (dyspnoea, lack of appetite, sleeping disorders, constipation, diarrhoea and financial problems). In each scale $0-100$ points can be achieved whereby higher point numbers on the five function scales and the general quality of life scale are indicative of a better function, whereas high point numbers in the symptom-oriented scales and items point to more highly pronounced symptoms. The EORTC QLQ-C30 is a reliable and valid measurement tool [30] and is often employed in clinical trials.

In order to collect disease-specific and treatment-specific aspects of the quality of life of cervical cancer patients, the EORTC QLQCX24 (The European Organisation for Research and Treatment of Cancer Quality-of-Life Questionnaire Cervical Cancer Module) with its 24 items was used. This additional module to the EORTC QLQ-C30 contains three multi-item scales (body image, sexual and vaginal function), symptom experience from the vaginal, gastrointestinal and urological fields as well as six single item scales. The higher the number of points (range 0-100) the stronger are the symptoms pronounced or, respectively, the poorer is the sexual vaginal function. Sole exceptions are the items positive sexual responsiveness and sexual activity, for which a higher number of points is indicative of better functioning in these fields. The EORTC QLQ-CX24 possesses a good internal consistency with a Cronbach's alpha in the range 0.72-0.87 [31,32].

\section{Evaluation}

SPSS 18.0 was employed for the statistical analyses. The data were also evaluated descriptively (absolute and percent frequencies, mean values, standard deviations) and subsequently checked for statistically relevant differences between the study groups. For this the $\mathrm{X}^{2}$ test or, respectively Fisher's exact test for categorical variables, the Mann-Whitney U test for not normally distributed variables and the test for normally distributed variables were employed. With the help of covariance analyses, mean value differences between the study groups were examined under consideration of the confounders "age at interview" and
Table 1 Sociodemographic and medical description of the study populations.

\begin{tabular}{|c|c|c|c|}
\hline & $\begin{array}{l}\text { TMMR } \\
\text { patients } \\
(n=74)\end{array}$ & $\begin{array}{l}\text { RH } \\
\text { patients } \\
(n=36)\end{array}$ & $\begin{array}{l}\text { Test for } \\
\text { group dif- } \\
\text { ferences }\end{array}$ \\
\hline \multicolumn{4}{|l|}{ Sociodemographic details } \\
\hline Age & $\begin{array}{l}\text { mean } 44.6 \\
\text { years } \\
(\text { SD 10.0) }\end{array}$ & $\begin{array}{l}\text { mean } 54.8 \\
\text { years } \\
(\text { SD 14.7) }\end{array}$ & $p<0.001$ \\
\hline - Age range & $\begin{array}{l}30-70 \\
\text { years }\end{array}$ & $\begin{array}{l}30-85 \\
\text { years }\end{array}$ & \\
\hline Partnership & $63(85.1 \%)$ & $23(63.9 \%)$ & $p=0.011$ \\
\hline Own children & $67(90.5 \%)$ & $33(91.7 \%)$ & $p=1.000$ \\
\hline \multicolumn{4}{|l|}{ Stratification index } \\
\hline - Lower class & $3(4.5 \%)$ & $3(9.7 \%)$ & $p=0.534$ \\
\hline - Middle class & $58(77.6 \%)$ & $26(71.0 \%)$ & \\
\hline - Upper class & $13(17.9 \%)$ & $7(19.4 \%)$ & \\
\hline \multicolumn{4}{|l|}{ Medical details } \\
\hline \multicolumn{4}{|l|}{ Diagnosis } \\
\hline - Squamous cell carcinoma & $52(70.3 \%)$ & $21(58.3 \%)$ & $p=0.004$ \\
\hline - Adenocarcinoma & $18(24.3 \%)$ & $5(13.9 \%)$ & \\
\hline $\begin{array}{l}\text { - Cervical cancer not } \\
\text { exactly defined }\end{array}$ & $4(5.4 \%)$ & $10(27.8 \%)$ & \\
\hline \multicolumn{4}{|l|}{ Tumour stage } \\
\hline - FIGOI & $56(75.7 \%)$ & $29(80.6 \%)$ & $p=0.870$ \\
\hline > FIGOII & $17(23.0 \%)$ & $7(19.4 \%)$ & \\
\hline - not applicable, recurrence & $1(1.4 \%)$ & $0(0 \%)$ & \\
\hline \multicolumn{4}{|l|}{ Therapy in addition to operation } \\
\hline - None & $60(81.1 \%)$ & $19(52.8 \%)$ & $p<0.001$ \\
\hline - Chemotherapy & $14(18.9 \%)$ & $0(0 \%)$ & \\
\hline - Radio- and chemotherapy & $0(0 \%)$ & $6(16.7 \%)$ & \\
\hline - Radiotherapy & $0(0 \%)$ & $11(30.6 \%)$ & \\
\hline \multicolumn{4}{|l|}{ Menopausal status } \\
\hline - Premenopausal & $14(19.2 \%)$ & $7(19.4 \%)$ & $p=0.002$ \\
\hline - Postmenopausal & $14(19,2 \%)$ & $18(50.0 \%)$ & \\
\hline $\begin{array}{l}\text { Menopause induced } \\
\text { by treatment }\end{array}$ & $45(61.6 \%)$ & $11(30.6 \%)$ & \\
\hline $\begin{array}{l}\text { Time point of Therapy } \\
\text { (time elapsed between therapy } \\
\text { and interview) }\end{array}$ & $\begin{array}{l}29.51 \\
\text { months } \\
(\text { SD 18,18) }\end{array}$ & $\begin{array}{l}41.14 \\
\text { months } \\
\text { (SD 25.92) }\end{array}$ & $p=0.019$ \\
\hline
\end{tabular}

$\mathrm{SD}=$ standard deviation

"time elapsed between treatment and interview". All statistical tests were two-sided and the significance level was set at $\mathrm{p}<0.05$.

\section{Results}

$\nabla$

\section{Description of the study population}

Of the 141 patients who received a written invitation or, respectively, were personally approached (110 from Leipzig University hospital), 118 fulfilled the inclusion criteria. 20 patients received other treatments in place of TMMR or RH and in three patients the FIGO stage was higher than II. Of these 118 women, six refused to participate in the study, one woman had an insufficient knowledge of German and one patient was excluded due to insufficient data in her clinical record. Finally 110 patients were enrolled in the study (response rate 94\%). The final sample population consisted of 74 patients who had undergone TMMR treatment and 36 patients who had had a radical hysterectomy. Characteristic data of the study population are given in $\bullet$ Table 1 .

The average age was 44.6 years for the TMMR group and 54.8 years for the RH group ( $\mathrm{p}=0.001)$. Patients in the TMMR groups were living with a partner more frequently than those in the $\mathrm{RH}$ 
Table 2 Quality of life of the study populations and calculated analyses of covariance.

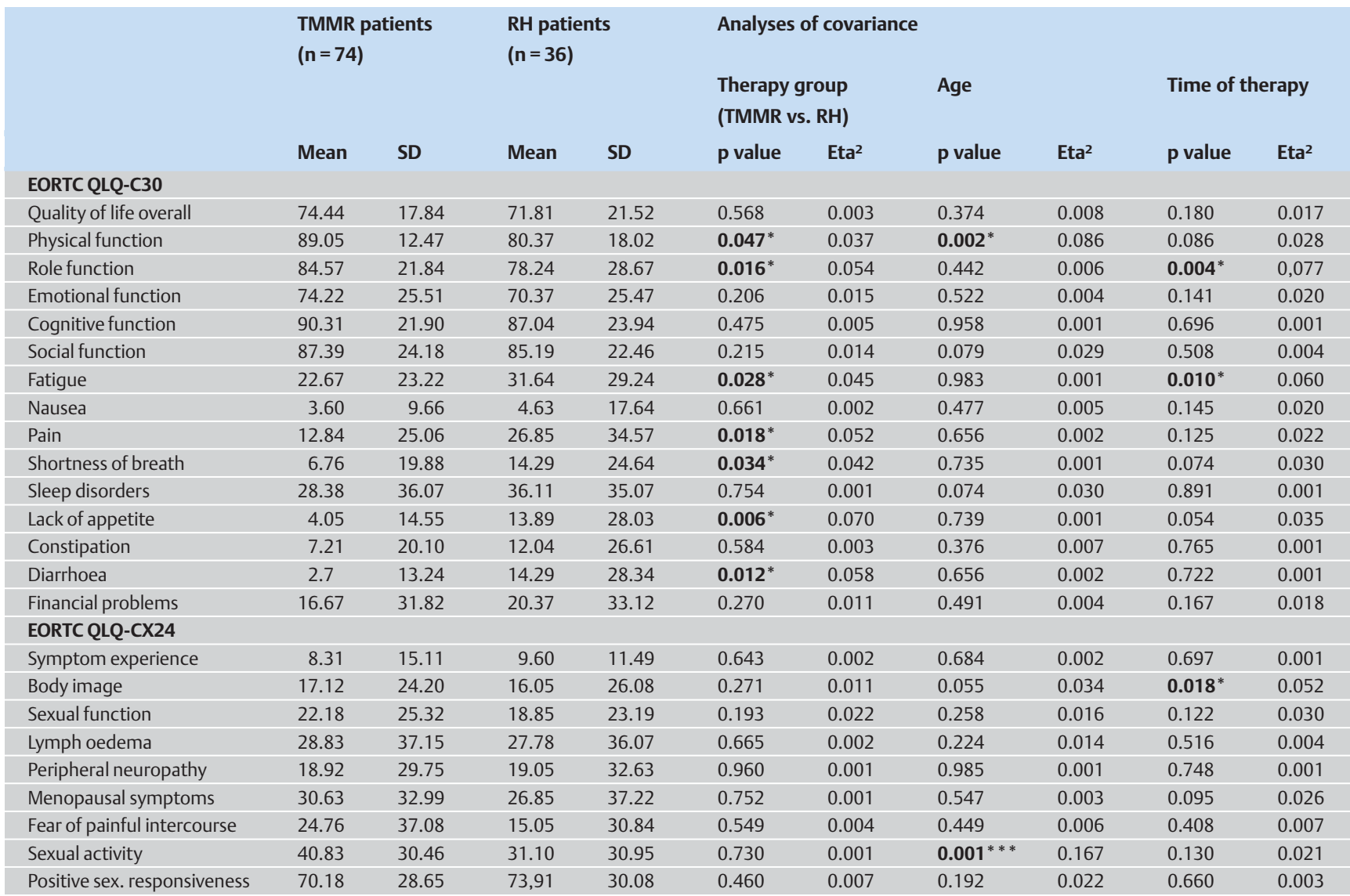

${ }^{*} \mathrm{SD}=$ standard deviation; $\mathrm{Eta}^{2}=$ effect strength; $\mathrm{p}$ value: $<0.05 ;{ }^{* *} \mathrm{p}$ value $<0.01 ;{ }^{* * *} \mathrm{p}$ value $<0.001$

group $(\mathrm{p}=0.011)$. With regard to own children and stratification index, there were no differences between the groups.

The histological diagnosis for more than half of the women was squamous cell carcinoma of the uterine cervix; one in five women had an adenocarcinoma. With regard to FIGO stages, at least for stage I and the appearance of a recurrence, there were no significant differences between the two groups. Concerning menopausal status it was found that more participants in the TMMR group were in menopause induced by treatment while in the $\mathrm{RH}$ group more women were in a postmenopausal state $(\mathrm{p}=0.002)$. Markedly more patients of the $\mathrm{RH}$ group received a neoadjuvant/adjuvant radiotherapy or, respectively a combined chemoand radiotherapy $(\mathrm{p}=0.001)$. The investigated groups differed significantly in the mean value of the time elapsed between surgical therapy and interview $(\mathrm{p}=0.019)$. Here, the TMMR group experienced a shorter time between therapy and interview than the RH group.

\section{Quality of life}

For the function scales of the EORTC QLQ-C30 ( Table 2), it is seen that the mean values in both groups were always more than 70 points and thus indicative of a relatively good quality of life in these areas. The mean values in the TMMR group were, with the exception of positive sexual responsiveness, always higher than those of the RH group when considered descriptively. With regard to the scale overall quality of life, there were no differences between the two study groups. Neither age at the time of interview nor the time elapsed between therapy and interview had a relevant influence on the scale overall quality of life.

\section{Physical level}

With regard to physical function $(p=0.047)$, fatigue $(p=0.028)$, pain $(p=0.018)$, shortness of breath $(p=0.034)$, lack of appetite $(p=0.006)$ and diarrhoea $(p=0.012)$ the quality of life in the TMMR group was significantly better in comparison to the $\mathrm{RH}$ group. For the results concerning pain and diarrhoea, the differences are of a clinically relevant order of magnitude since there are mean value differences on more than 10 points [33].

For the symptom scales nausea, constipation, peripheral neuropathy, menopausal symptoms, lymph oedema and symptom experience, no significant differences in mean values could be determined. Age had a significant influence on physical function. Here, the corresponding correlation analysis revealed a reciprocal relationship (age: $r=-0.347 ; p=0.001$ ). The time elapsed between therapy and interview had an impact on the experience of fatigue. This was also an inverse relationship (fatigue: $r=-0.194$; $\mathrm{p}=0.042$ ). For all other scales or, respectively, items no influence of the control variables was found.

\section{Mental level}

For the scales emotional function, body image and sleeping disorders, no significant differences were detected between the 
study groups. With regard to the control variables, only the time elapsed between therapy and interview had a significant influence on body image. This was again an inverse relationship $(\mathrm{r}=-0.243 ; \mathrm{p}=0.010)$.

\section{Social level}

The mean value for the scale role function was statistically significantly higher in the TMMR group than that in the RH group. There were no significant differences between the mean values for the scales financial problems and social function for the two groups. Examination of the control variables revealed that the time elapsed between therapy and interview had a significant influence on the role function. This correlation was positive $(\mathrm{r}=0.238 ; \mathrm{p}=0.012)$.

\section{Sexual level}

Statistically significant group differences were not detected for sexual vaginal function, sexual activity, fear of painful intercourse and positive sexual responsiveness. Only age at interview had a statistically significant influence on sexual activity. This was a reciprocal relationship $(r=-0.443 ; p=0.001)$.

\section{Discussion}

$\nabla$

The object of this study was to compare the postoperative healthrelated quality of life between cervical cancer patients who had undergone treatment by two different surgical procedures (radical hysterectomy as standard therapy and TMMR as nerve-sparing surgical technique).

The interviewed patients did not differ in terms of overall quality of life. This finding is in accord with previous results that also could not detect any relevant differences with regard to overall quality of life between groups receiving different treatment regimens $[18,19,24,34]$.

\section{Physical level}

Most of the differences in the therapy groups were in the physical field. Thus, physical functioning after a TMMR operation was 9 points better than that after radical hysterectomy. This can be attributed to the fact that radiotherapy is generally not necessary after TMMR. Thus, Greimel et al. [34] stated that patients not undergoing radiotherapy reported having a higher physical functioning than those patients who received radiotherapy in addition to radical hysterectomy. Analogous results were also described by Miller et al. [35]. In contrast, however, other studies did not detect any influence of radiotherapy on physical functioning $[18,19,36,37]$. A further possible reason is the nervesparing aspect of the treatment. In this respect the currently available studies also could not detect any differences in physical functioning $[24,27]$. The heterogeneity of the findings is possibly due to the limited comparability of the studies. Thus, in the study of Frumovitz et al. [36] the therapy took place 5 years earlier and radical hysterectomies alone were compared with radiotherapy alone. The latter also holds for the study of Hsu and co-workers [19]. Furthermore, the authors did not give any details of the response rate and about a possible selectivity bias of their sample population. Korfage et al. [37] found systematic differences between responders and non-responders in their investigation which could possibly have led to a distortion of the results.

Fatigue is a typical symptom not only of cancer patients in general but also of cervical cancer patients in particular $[18,38,39]$. In our study women who received TMMR as treatment exhibited a lower level of fatigue symptoms than women who had undergone the standard operation. According to a review by JereczekFossa [40] fatigue is a frequent symptom of radiotherapy. With regard to therapy for cervical cancer, an influence of the type of treatment with regard to fatigue could not be demonstrated with sufficient certainty $[18,19,34]$. The mean value for the symptom pain was, in our study, two-times higher in the standard treatment group than in the TMMR group. This observed difference may be due to the fact that some of the patients in the $\mathrm{RH}$ group also received an additional radiotherapy. Thus Greimel et al. [34] reported significantly higher pain values for patients who received an adjuvant radiotherapy in comparison to those women who were not irradiated. The study by Hsu et al. [19] revealed that cervical cancer patients who received radiotherapy suffered significantly more frequently from abdominal pain than did surgically treated patients. On the other hand, other authors did not find any influence of the therapeutic regimen on the occurrence of pain $[18,37]$. Women who had undergone the standard operation suffered significantly more often from diarrhoea than did patients in the TMMR group. Previous studies support the finding that especially cervical cancer patients who had received radiotherapy subsequently suffer more frequently from diarrhoea [19, 41]. Thus, in the study by Hsu et al. [19], 43.2\% of the irradiated patients reported this symptomatology as compared to merely $6.6 \%$ patients of the surgically treated patients. Only Greimel et al. [34] could not find any difference regarding diarrhoea between the investigated therapy groups.

With regard to the symptoms shortness of breath and lack of appetite, significant mean value differences between the two investigated groups were found in favour of the TMMR group. From a pathophysiological viewpoint these results are at first difficult to attribute to an influence of radiotherapy or the surgical technique. Except for the study by Greimel et al. [34], which also failed to provide an explanation for the respective results, as yet no study has found a significant influence of either radiotherapy or the nerve-sparing surgical method on the symptoms shortness of breath and lack of appetite [18, 19,24].

\section{Mental level}

Like most of the previous research works $[19,24,34,35,37]$ the present study did not uncover any differences between the various therapy groups with regard to emotional function, sleeping disorders and impairments of body image.

\section{Social level}

Whereas the women who had had a TMMR operation estimated the role function better than did the women who received the standard therapy, no differences with regard to social function and financial problems could be found between the therapy groups. Wu et al. [27] also demonstrated that cervical cancer patients who had undergone a nerve-sparing operation could pursue their activities of daily life better than those women who had received the standard therapy. Other studies, in contrast, did not find any influence of therapy in the social field $[18,19,37]$.

\section{Sexual level}

In the field of sexuality no significant differences between the two therapy groups were detected. However, the data in this aspect are inconsistent. Some studies came to the conclusion that radiotherapy may have a negative impact on sexuality $[15,22$, $34,37,42]$. And there are also hints that the nerve-sparing opera- 
tion can have a positive influence with regard to sexuality [43, 44]. One reason for the discrepancy between these two plausible hypotheses and the present results could be the small sizes of the groups which resulted due to the complete absence of sexual activity in many of the women (TMMR: $n=59$; RH: $n=23$ ). In addition many more than half of the women in the $\mathrm{RH}$ groups did not receive radiotherapy. More scientifically based research is necessary to provide evidence for this point.

\section{Limitations}

Even when the validity of a retrospective explorative cross-sectional study is limited, it must be mentioned that with this study the quality of life of cervical cancer patients operated with the nerve-sparing TMMR procedure and with the standard method has been compared for the first time. As methodological criticisms it must be stated that structural comparability of the two treatment groups with regard to relevant characteristics (e.g., age menopausal status) was not completely realised. On account of the sample sizes not all possible influencing factors in which the two groups differed could be checked in the statistical analyses. Also, even with subgroup analyses no meaningful results about the variable forms in the two groups can be expected due to the small number of cases. The influence of the variables age and time elapsed between therapy and interview, however, could be taken into consideration in the multivariate analyses. A further limitation arises from the relationship with the investigated sample sizes on account of the relatively low incidence and the resulting treatment numbers for cervical cancer. An adequate power of at least $80 \%$ was obtained here merely for the detection of medium to large effects. Those results for which no differences between the investigated therapeutic methods were postulated must be interpreted with due caution. Finally, it must be noted that on account of the explorative character of the investigation an adjustment of the alpha level with regard to alpha error accumulation in the course of multiple testing had to be omitted.

The present findings are suggestive of a comparable or, respectively, in some fields better quality of life for cervical cancer patients after TMMR treatment in comparison to patients who underwent a radical hysterectomy. A superiority of TMMR in comparison to the current standard therapy with regard to the areas postoperative physical functioning and role function concerning the symptoms fatigue, pain, dyspnoea, lack of appetite and diarrhoea was demonstrated. These results may be interpreted as a suggestion that a nerve-sparing operation and the possibility to do without an additional radiotherapy have a positive impact on the quality of life for the women. This must be verified in future studies and robust results must be obtained in the field of postoperative quality of life for cervical cancer patients in dependence on the various therapeutic methods. The influence of nerve-sparing surgical methods such as TMMR is of particular interest in this context.

\section{Conclusions for the Practitioner}

\section{$\nabla$}

The TMMR operation is a new, nerve-sparing procedure for cervical cancer patients by which, according to the available data and with appropriate informed consent of the patient, an additional radiotherapy can be omitted. The results of our explorative study on the quality of life are suggestive of a superiority of TMMR in comparison to the current standard procedure of radical hysterectomy according to Wertheim-Meigs, especially in the physical fields and fatigue. However these results still require further confirmation.

\section{Conflict of Interest}

\section{$\nabla$}

None.

\section{References}

1 Robert Koch-Institut; Gesellschaft der epidemiologischen Krebsregister in Deutschland e.V., Hrsg. Krebs in Deutschland 2007/2008. 8. Ausgabe. Berlin: 2012

2 Waldmann A, Eisemann N, Katalinic A. Epidemiology of malignant cervical, corpus uteri and ovarian tumours - current data and epidemiological trends. Geburtsh Frauenheilk 2013; 73: 123-129

3 Walboomers JM, Jacobs MV, Manos MM et al. Human papillomavirus is a necessary cause of invasive cervical cancer worldwide. J Pathol 1999; 189: $12-19$

4 Simoes E, Brucker S, Beckmann MW et al. Screening for cervical cancerminimise risks - maximise benefits. Need for adaptation in Germany in light of the European guidelines and their objectives. Geburtsh Frauenheilk 2013; 73: 623-639

5 Simoes E, Brucker S, Beckmann MW et al. Cervical cancer screening: defining the need for research. Geburtsh Frauenheilk 2013; 73: 239-246

6 Juhasz-Böss I, Mallmann P, Möller CP et al. Use of laparoscopy in the treatment of endometrial and cervical cancer - results of a 2012 Germany-wide survey. Geburtsh Frauenheilk 2013; 73: 911-917

7 Beckmann MW, Mallmann P. Interdisciplinary S2 k guideline on the diagnosis and treatment of cervical carcinoma. J Cancer Res Clin Oncol 2009; 35: 1197-1206

8 Mangler M, Zech N, Schneider A et al. Aspects of therapy for cervical cancer in Germany 2012 - Results from a survey of German gynaecological hospitals. Geburtsh Frauenheilk 2013; 73: 227-238

9 Höckel M, Horn LC, Fritsch H. Association between the mesenchymal compartment of uterovaginal organogenesis and local tumour spread in stage IB-IIB cervical carcinoma: a prospective study. Lancet Oncol 2005; 6: 751-756

10 Höckel M, Horn LC, Manthey N et al. Resection of the embryologically defined uterovaginal (Mullerian) compartment and pelvic control in patients with cervical cancer: a prospective analysis. Lancet Oncol 2009; 10: 683-692

11 Matsuura Y, Kawagoe T, Toki $N$ et al. Long-standing complications after treatment for cancer of the uterine cervix-clinical significance of medical examination at 5 years after treatment. Int J Gynecol Cancer 2006; 16: 294-297

12 Kashima K, Yahata T, Fujita $\mathrm{K}$ et al. Analysis of the complications after radical hysterectomy for stage IB, IIA and IIB uterine cervical cancer patients. J Obstet Gynaecol Res 2010; 36: 555-559

13 Landoni F, Maneo A, Colombo A et al. Randomised study of radical surgery versus radiotherapy for stage Ib-II a cervical cancer. Lancet 1997; 350: 535-540

14 Undurraga M, Loubeyre P, Dubuisson JB et al. Early-stage cervical cancer: is surgery better than radiotherapy? Expert Rev Anticancer Ther 2010; 10: 451-460

15 Vrzackova P, Weiss P, Cibula D. Sexual morbidity following radical hysterectomy for cervical cancer. Expert Rev Anticancer Ther 2010; 10: 1037-1042

16 Baalbergen A, Veenstra $Y$, Stalpers $L L$ et al. Primary surgery versus primary radiation therapy with or without chemotherapy for early adenocarcinoma of the uterine cervix. Cochrane Database Syst Rev 2010; 1: CD006248

17 Goncalves $V$. Long-term quality of life in gynecological cancer survivors. Curr Opin Obstet Gynecol 2010; 22: 30-35

18 Park SY, Bae DS, Nam JH et al. Quality of life and sexual problems in disease-free survivors of cervical cancer compared with the general population. Cancer 2007; 110: 2716-2725

19 Hsu WC, Chung NN, Chen YC et al. Comparison of surgery or radiotherapy on complications and quality of life in patients with the stage IB and IIA uterine cervical cancer. Gynecol Oncol 2009; 115: 41-45

20 Ebert $A D$, Ulrich $U$, Beckmann MW et al. [Unanswered questions in the management of cervical cancer]. Zentralbl Gynakol 2006; 128: 23-26

21 Dursun P, Ayhan A, Kuscu E. New surgical approaches for the management of cervical carcinoma. Eur J Surg Oncol 2008; 34: 487-496 
22 Dursun P, Ayhan A, Kuscu E. Nerve-sparing radical hysterectomy for cervical carcinoma. Crit Rev Oncol Hematol 2009; 70: 195-205

23 Rob L, Halaska M, Robova $H$. Nerve-sparing and individually tailored surgery for cervical cancer. Lancet Oncol 2010; 11: 292-301

24 Ditto A, Martinelli F, Borreani C et al. Quality of life and sexual, bladder, and intestinal dysfunctions after class III nerve-sparing and class II radical hysterectomies: a questionnaire-based study. Int J Gynecol Cancer 2009; 19: 953-957

25 Raspagliesi F, Ditto A, Fontanelli R et al. Nerve-sparing radical hysterectomy: a surgical technique for preserving the autonomic hypogastric nerve. Gynecol Oncol 2004; 93: 307-314

26 Raspagliesi F, Ditto A, Kusamura S. Nerve-sparing radical hysterectomy: a pilot study. Tumor 2003; 89: 497-501

$27 \mathrm{Wu}$ J, Liu X, Hua K et al. Effect of nerve-sparing radical hysterectomy on bladder function recovery and quality of life in patients with cervical carcinoma. Int J Gynecol. Cancer 2010; 20: 905-909

28 Fujii S. Anatomic identification of nerve-sparing radical hysterectomy: a step-by-step procedure. Gynecol Oncol 2008; 111 (2 Suppl.): S33S41

29 Fujii S, Takakura K, Matsumura N. Anatomic identification and functional outcomes of the nerve sparing Okabayashi radical hysterectomy. Gynecol Oncol 2007; 107: 4-13

30 Aaronson NK, Ahmedzai S, Bergman B et al. The European Organization for Research and Treatment of Cancer QLQ-C30: a quality-of-life instrument for use in international clinical trials in oncology. J Natl Cancer Inst 1993; 85: 365-376

31 Greimel ER, Kuljanic VK, Waldenstrom AC et al. The European Organization for Research and Treatment of Cancer (EORTC) Quality-of-Life questionnaire cervical cancer module: EORTC QLQ-CX24. Cancer 2006; 107: 1812-1822

32 Singer S, Kuhnt S, Momenghalibaf A et al. Patients' acceptance and psychometric properties of the EORTC QLQ-CX24 after surgery. Gynecol Oncol 2010; 116: 82-87

33 Osoba D, Rodrigues G, Myles $J$ et al. Interpreting the significance of changes in health-related quality-of-life scores. J Clin Oncol 1998; 16: 139-144
34 Greimel ER, Winter R, Kapp KS et al. Quality of life and sexual functioning after cervical cancer treatment: a long-term follow-up study. Psychooncology 2009; 18: 476-482

35 Miller BE, Pittman B, Case D et al. Quality of life after treatment for gynecologic malignancies: a pilot study in an outpatient clinic. Gynecol Oncol 2002; 87: 178-184

36 Frumovitz M, Sun CC, Schover LR. Quality of life and sexual functioning in cervical cancer survivors. J Clin Oncol 2005; 23: 7428-7436

37 Korfage IJ, Essink-Bot ML, Mols F. Health-related quality of life in cervical cancer survivors: a population-based survey. Int J Radiat Oncol Biol Phys 2009; 73: 1501-1509

38 Bloom JR, Petersen DM, Kang SH. Multi-dimensional quality of life among long-term (5+ years) adult cancer survivors. Psychooncology 2007; 16: 691-706

39 Vistad I, Fossa SD, Kristensen GB et al. Chronic fatigue and its correlates in long-term survivors of cervical cancer treated with radiotherapy. BJOG 2007; 114: 1150-1158

40 Jereczek-Fossa BA, Marsiglia HR, Orecchia R. Radiotherapy-related fatigue. Crit Rev Oncol Hematol 2002; 41: 317-325

41 Vistad I, Cvancarova M, Fossa SD et al. Postradiotherapy morbidity in long-term survivors after locally advanced cervical cancer: how well do physicians' assessments agree with those of their patients? Int J Radiat Oncol Biol Phys 2008; 71: 1335-1342

42 Pieterse $Q D$, Maas CP, Ter Kuile MM et al. An observational longitudinal study to evaluate miction, defecation, and sexual function after radical hysterectomy with pelvic lymphadenectomy for early-stage cervical cancer. Int J Gynecol Cancer 2006; 16: 1119-1129

43 Bradley S, Rose S, Lutgendorf S et al. Quality of life and mental health in cervical and endometrial cancer survivors. Gynecol Oncol 2006; 100: 479-486

44 Klee M, Thranov I, Machin D. Life after radiotherapy: the psychological and social effects experienced by women treated for advanced stages of cervical cancer. Gynecol Oncol 2000; 76: 5-13 